\title{
MODEL-FREE OUTPUT FEEDBACK CONTROLLER DESIGN FOR TWIN ROTOR SYSTEMS
}

\author{
Meryem DENIZ, Department of Mechanical and Aerospace Engineering, Missouri Science and Technology University, USA, \\ mdy7c@mst.edu
}

(iD https://orcid.org/0000-0001-5677-9584)

Enver TATLICIOĞLU*, Department of Electrical \& Electronics Engineering, Izmir Institute of Technology, Turkey, envertatlicioglu@iyte.edu.tr

(iD) https://orcid.org/0000-0001-5623-9975)

Alper BAYRAK, Department of Electrical and Electronics Engineering, Bolu Abant Izzet Baysal University, Turkey, alperbayrak@ibu.edu.tr

(iD) https://orcid.org/0000-0003-4745-5304)

Received: 03.12.2019, Accepted: 20.05.2020

*Corresponding author Research Article
DOI: $10.22531 /$ muglajsci.652372

\begin{abstract}
In this work, tracking control of twin rotor systems is aimed. The control problem is restricted by the lack of mathematical model of the twin rotor and further complicated by the unavailability of the angular velocity measurements. A model-free controller in conjunction with a high gain observer is designed. Experiments performed on a twin rotor system demonstrates the viability of the controller-observer couple.
\end{abstract}

Keywords: Twin rotor system, Model-free controller, Observer.

\section{ÇİFT ROTORLU SİSTEMLER İÇİN MODEL GEREKTİRMEYEN ÇIKIŞ GERİ BESLEMELİ DENETÇİ TASARIMI}

\section{Özet}

Bu çalışmada çift rotorlu sistemlerin yörünge takibi amaçlanmıştır. Çift rotorlu sistemin matematiksel modelinin belirsizlikler içermesi ve açısal hız ölçümlerinin bulunmaması denetim problemini zorlaștırmakta ve karmașılklaștırmaktadır. Bu sebeple, yüksek kazançlı bir gözlemciyle birleștirilmiş model bilgisi gerektirmeyen bir denetleyici tasarlanmıştır. Çift rotorlu sistem üzerinde yapılan deneyler, denetleyici-gözlemci ikilisinin etkinliğini göstermiştir.

Anahtar Kelimeler: Çift rotorlu sistem, Model gerektirmeyen denetçi, Gözlemci.

Cite

Deniz, M., Tatlıcıoğlu, E., Bayrak, A., (2020). “Model-free output feedback controller design for twin rotor systems”, Mugla Journal of Science and Technology, 6(1), 89-94.

\section{Introduction}

Twin rotor system is a laboratory setup resembling a simplified helicopter model that moves on both horizontal and vertical axes. In a twin rotor system, two rotors, named as main rotor and the tail rotor, adjust the angular positions on pitch and yaw axes. The main rotor directly adjusts the movement of the nose of twin rotor system up or down, while the tail rotor causes side to side movement of the nose of the twin rotor system. There are some commercial twin rotor systems developed by companies while there are only a few developed in an academic setting ([1], [2], [3]). Feedback Instruments Limited has produced a twin rotor system for educational purposes and control experiments. Quanser Inc. has also developed experimental helicopter systems.
The twin rotor system is highly nonlinear due to significant amount of cross-coupling between the two motion axes and the system does not have a common dynamic model due to aerodynamic effects being hard to model. Researchers investigated different parts of dynamic modelling with various techniques. [4] presented modelling of one degree of freedom (dof) motion of a twin rotor system by using black box system identification technique. [5] used black box system identification technique to obtain dynamic model of two dof twin rotor systems. [6] utilized both analytical and empirical approaches for modelling of twin rotor system. [7] obtained dynamic model of a twin rotor system with grey box system identification technique. [8] used artificial neural network based modelling to characterize the dynamic behaviour of one dof motion of a twin rotor system about the vertical plane. They utilized multi- 
layered perceptron neural networks by using LevenbergMorquardt based training algorithm and Elman recurrent neural networks to identify the dynamics of the system. [9] developed nonlinear dynamic model of a twin rotor system based on feed-forward neural networks by using resilient propagation algorithm to obtain a model via using optimum number of neurons. However, as it is apparent from the literature there is no commonly agreed on dynamic model for these systems. When it comes to control design, the parametric uncertainties in the model and the unmodelled effects due to the shortcomings of the modelling approaches mandates the use of model-free controllers. Most of these controllers utilized the signum function in their designs to compensate for uncertainties ([1], [10], [11], [12]) while other robust control techniques were also utilized.

While lack of accurate dynamic models were addressed via robust terms in the control designs, almost all of these past works considered full-state feedback as both angular position and angular velocity measurements were required to implement the controllers ([1], [10], [12], [13], [14], [15], [16]). Only a few results considered output feedback (i.e., only angular position information being available) ([11], [17], [18], [19]).

The lack of accurate dynamic models and angular velocity measurements constituted the main motivation of this work. As a novel departure from the existing control literature on twin rotor systems, a completely model-free controller formulation with only angular position feedback is aimed. To address the lack of angular velocity measurements, a model-free high gain observer is utilized. Then a simple controller is proposed. The controller makes use of observer terms in conjunction with a feed-forward component. The observer term is saturated to ensure boundedness of the control input and to avoid peaking phenomenon ([20]). In the case of partial model knowledge being available, that information can be used as the feed-forward component or artificial intelligence like methods such as neural networks similar to the work of [12] can be utilized.

The rest of the paper is organized in the following manner. Dynamic model for twin rotor system is given in Section 2. Observer and controller formulations are developed in Section 3. Experimental results are given in Section 4, and conclusions are given in Section 5.

\section{Dynamic Model of a Twin Rotor System}

The mathematical model for a twin rotor system can be represented by $([21])$

$$
M(\theta) \ddot{\theta}+N(\theta, \dot{\theta}, t)=\tau(t)
$$

where $\theta(t), \dot{\theta}(t), \quad \ddot{\theta}(\mathrm{t}) \in \mathbb{R}^{2}$ represent the angular position, velocity and acceleration vectors, respectively, $M(\theta) \in \mathbb{R}^{2 x 2}$ represents the inertia matrix, $N(\theta, \dot{\theta}, t) \in$ $\mathbb{R}^{2}$ represents Centripetal and Coriolis effects, and $\tau(t) \in \mathbb{R}^{2}$ represents the control input vector. Twin rotor system moves on both horizontal and vertical axes, therefore, $\theta(t)$ is defined as the combination of yaw and pitch motions in the sense that $\theta=\left[\theta_{h}, \theta_{v}\right]^{T}$ with $\theta_{h}(t)$ and $\theta_{v}(t)$ denoting horizontal and vertical angular positions, respectively ([12]).

Assumption 1. The inertia matrix is symmetric and positive definite and satisfies the following inequalities ([12], [21])

$$
m_{1}\|\xi\|^{2} \leq \xi^{T} M(\theta) \xi \leq m_{2}\|\xi\|^{2}
$$

where $\forall \xi \in \mathbb{R}^{2}$ and $m_{1}$ and $m_{2}$ are positive bounding constants.

\section{Observer \& Controller Design}

The main control objective is to control both angular pitch and yaw positions to track desired trajectories. The control problem is restricted by only the angular positions being measurable. This problem will be addressed via the design of an observer. Furthermore, the dynamical terms $\mathrm{M}$ and $\mathrm{N}$ are considered to include both parametric and unstructured uncertainties and thus cannot be utilized in the design of neither the observer nor the controller. As a result, both observer and controller should be model-free.

To initiate the design of the robust output feedback controller, the tracking error $e(t) \in \mathbb{R}^{2}$ is defined as

$$
e \doteq \theta_{d}-\theta
$$

where $\theta_{d}(\mathrm{t}) \in \mathbb{R}^{2}$ is the desired angular position. It is assumed that the desired angular position is sufficiently smooth. An auxiliary filtered error, $r(t) \in \mathbb{R}^{2}$, is defined as

$$
r \doteq \dot{e}+\gamma e
$$

where $\gamma \in \mathbb{R}^{2 x 2}$ is a positive definite diagonal gain matrix. Since only output feedback is available, we will follow an observer based strategy. Firstly, an observed filtered error, denoted by $\dot{\hat{r}} \in \mathbb{R}^{2}$, is designed as

$$
\dot{\hat{r}} \doteq \frac{1}{\epsilon^{2}} \alpha_{2}(e-\hat{e})
$$

with $\hat{e} \in \mathbb{R}^{2}$ being the observed position error that is updated according to

$$
\dot{\hat{e}}=\hat{r}-\gamma \hat{e}+\frac{1}{\epsilon} \alpha_{1}(e-\hat{e})
$$

where $\epsilon \in \mathbb{R}$ is a small positive constant, and $\alpha_{1}, \alpha_{2} \in \mathbb{R}^{2 x 2}$ are positive definite diagonal observer gain matrices.

The control input is designed as

$$
\tau=\operatorname{Sat}(K \hat{r})+\tau_{f f}
$$

where $K \in \mathbb{R}^{2 x 2}$ is positive definite diagonal control gain matrix, $\tau_{f f}(t) \in \mathbb{R}^{2}$ is the feed-forward component of the control input, and $\operatorname{Sat}(\cdot) \in \mathbb{R}^{2}$ is the vector saturation function. The feed-forward term is used to compensate for some parts of the unknown dynamics and can be set to zero without affecting the stability analysis. This choice of the feed-forward component will cause higher control gains but when this is an issue then feed-forward component could be made use of to compensate for some part of the uncertainties and thus relatively smaller control gains could be used. In the control design, saturation function is introduced to keep the control input bounded and to avoid the possibility of peaking phenomenon. When the dynamic model is partially available it can be utilized as the feed-forward 
component, and when there is no a priori knowledge of the dynamic model, neural networks can be utilized as the feed-forward component. Finally, it is clear that the control input can be obtained by only the measurements of $\theta(t)$.

Theorem. The controller in (7) with the observer design in (5) and (6) yields a semi global uniformly ultimately bounded tracking result in the sense that

$$
\|e(t)\| \leq \epsilon_{b}
$$

here $\epsilon_{b}$ is a known positive bounding constant that can be adjusted arbitrarily small.

Proof. See Appendix A.

\section{Experimental Results}

To show the effectiveness of the controller, experimental studies performed on a twin rotor system are given. The twin rotor system which is used in this study and shown in Figure 1 was developed in Control Laboratory of Electrical \& Electronics Engineering Department at Izmir Institute of Technology [3]. Labview was used as the software to monitor the twin rotor system and to provide online communication with it through the serial port.

Experimental results of the proposed controller are investigated for set-point control of the twin rotor system. The desired angular positions were chosen as 30 degrees and 20 degrees for pitch and yaw motions, respectively. The control gain matrices were chosen as $\mathrm{K}=\operatorname{diag}([10 ; 50]), \gamma=\operatorname{diag}([2 ; 2])$ and since satisfactory performance was obtained with only the feedback part of the controllers, feed-forward compensation term was not utilized. For the high gain observer, the observer gains were chosen as $\alpha_{1}=\alpha_{2}=\operatorname{diag}([10 ; 10])$, and $\epsilon=0.1$.

The results are shown in Figures 2-5. In Figure 2, the angular positions of both vertical (i.e., $\theta_{v}$ ) and horizontal (i.e., $\theta_{h}$ ) axes are presented. In Figure 3 , the position tracking error for both vertical and horizontal axes are given. In Figure 4, difference between actual and position observer error (i.e., $e(t)-\hat{e}(t)$ ) is presented. In Figure 5, control input voltage for both axes are given. From Figures 2 and 3, it can be seen that vertical angular position is unsmooth while horizontal angular positon is pretty smooth. This is caused by the different characteristics of the dynamics of vertical and horizontal movements. The tracking capability of such systems for vertical axes is usually not as good as the horizontal axes'. This situation also causes the vertical observation more difficult. However, from Figure 3, it is obvious that the control objective was achieved while it is clear that the observer error is driven to the vicinity of zero from Figure 4.

\section{Conclusions}

In this paper, we presented a new controller for twin rotor systems. In a novel departure from the existing works on twin rotor systems in the literature, the controller does not require neither system dynamics information nor angular velocity measurements. As a result, a simple model-free controller structure that requires only angular position measurements is proposed. The controller ensures uniform ultimate boundedness of the angular position tracking error and the observer errors. The performance of the controller and the high gain observer were verified via experimental studies on the twin rotor system.

As possible research avenues, the proposed controller may be applied to other experimental testbeds. In addition, the assumption which requires the desired position be sufficiently smooth will be tried to be relaxed to constitute a more general control strategy.

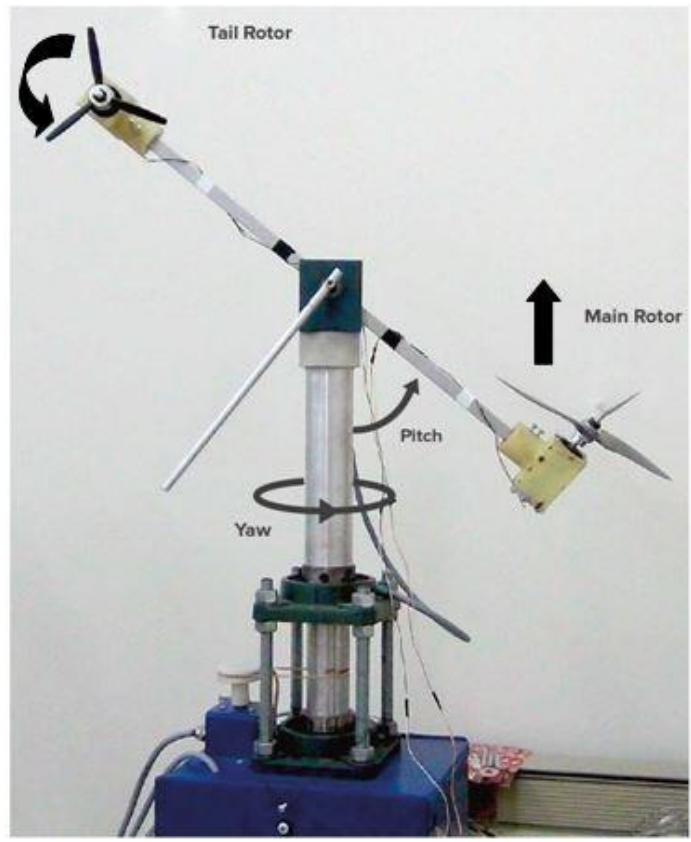

Figure 1: View of twin rotor system [3]

\section{References}

[1] Corradini, M. L., Cristofaro, A. and Orlando, G., "Stabilization of discrete-time linear systems with saturating actuators using sliding modes: Application to a twin-rotor system", in: IEEE Conf. on Decision and Control, Orlando, Florida, USA, 2011, p. 8237-8242.

[2] Verzilli, L., "Progetto e sviluppo di un controllore a struttura variabile per un twin rotor, Master's thesis", Universit'a Politecnica delle Marche, Ancona, Italy, 2007.

[3] Bayrak, A., Dogan F., Tatlicioglu E. and Ozdemirel B., "Design of an experimental twin-rotor multiinput multi-output system", Computer Applications in Engineering Education, v. 23, n. 4, p. 578-586, 2015.

[4] Ahmad, S., Chipperfield and A., Tokhi, M., "Dynamic modelling and linear quadratic gaussian control of a twin-rotor multi-input multi-output system", Proc. of the Institution of Mechanical Engineers, Part I: Journal of Systems and Control Engineering, v. 217, n. 3, p. 203-227, 2003. 

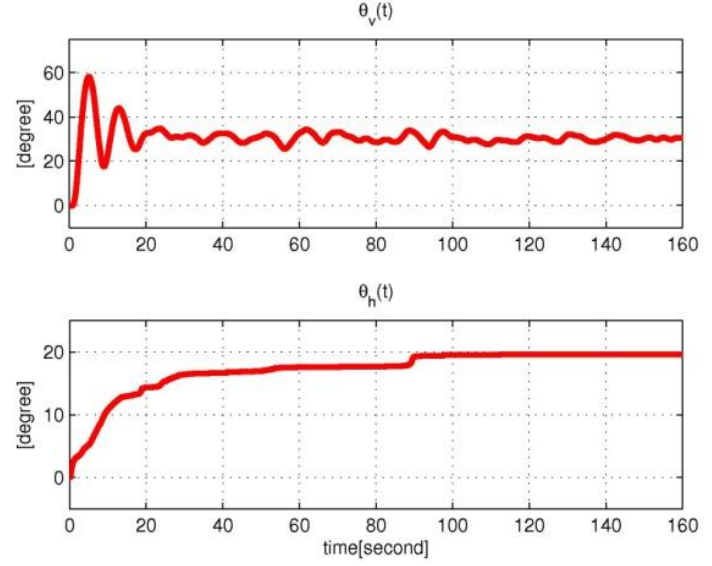

Figure 2: Vertical and horizontal angular positions
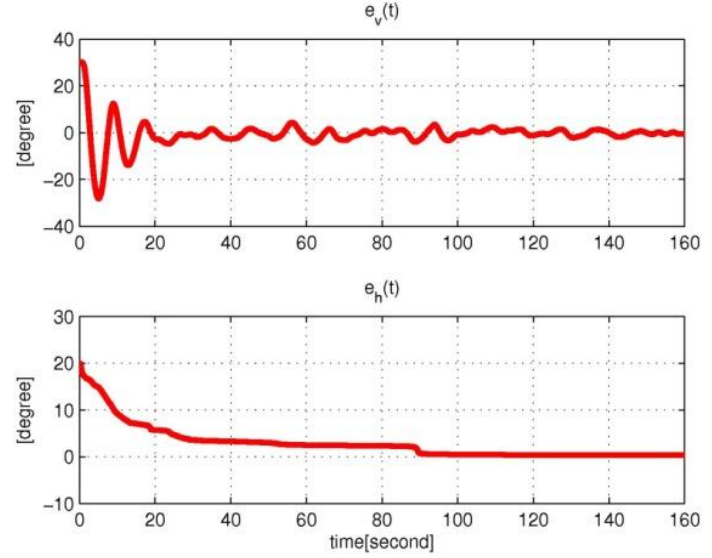

Figure 3: Vertical and horizontal tracking errors
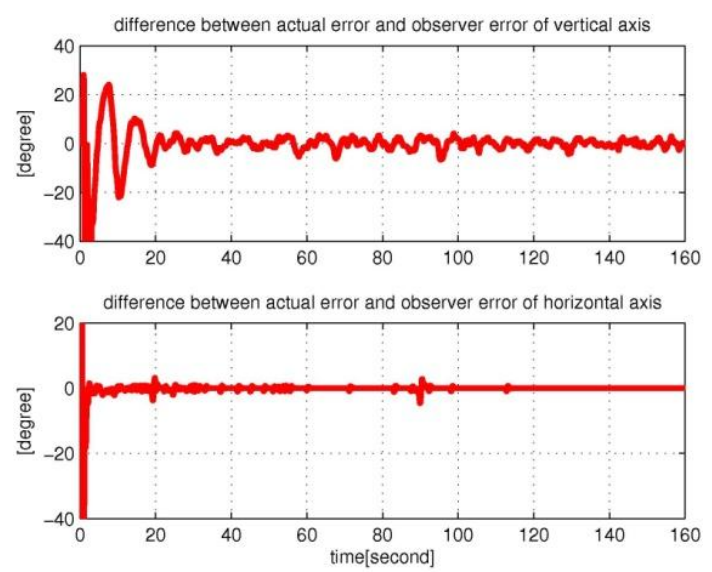

Figure 4: Differences between actual error and observed error for vertical and horizontal axes
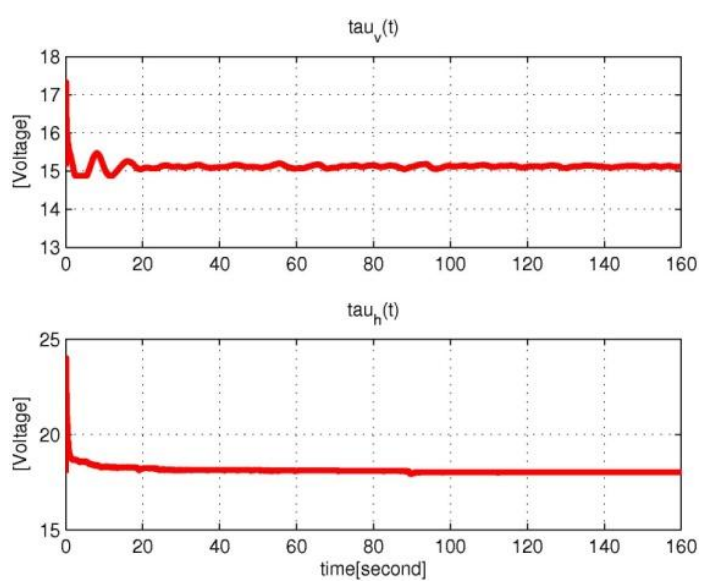

Figure 5: Control input voltages for main and tail rotors

[5] Ahmad, S., Chipperfield and A., Tokhi, M., "Dynamic modelling and open-loop control of a two-degreeof-freedom twin-rotor multi-input multi-output system", Proc. of the Institution of Mechanical Engineers, Part I: Journal of Systems and Control Engineering, v. 218, n. 6, p. 451-463, 2004.

[6] Rahideh, A., Shaheed, M. and Huijberts, H., "Dynamic modelling of a trms using analytical and empirical approaches", Control Engineering Practice, v. 16, n. 3, p. 241-259, 2008.

[7] Rahideh, A. and Shaheed, M. H., "Dynamic modelling of a twin rotor mimo system using grey box approach", in: Int. Symp. on Mechatronics and Its Applications, Amman, Jordan, 2008, p. 1-6.

[8] Toha, S. and Tokhi, M., "MLP and Elman recurrent neural network modelling for the TRMS", in: Int. Conf. on Cybernetic Intelligent Systems, London, UK, 2008, p. 1-6.

[9] Shaheed, H. M., "Feedforward neural network based non-linear dynamic modelling of a TRMS using rprop algorithm", Aircraft Engineering and Aerospace Technology, v. 77, n. 1, p. 13-22, 2005.

[10] Lu, T.-W. and Wen, P., "Time optimal and robust control of twin rotor system", in: Int. Conf. on Control and Automation, Guangzhou, China, 2007, p. 862-866.

[11] Choi, H. H., "Sliding-mode output feedback control design", IEEE Tr. On Industrial Electronics, v. 55, n. 11, p. 4047-4054, 2008.

[12] Rahideh, A., Shaheed, M. and Bajodah, A., "Neural network based adaptive non-linear model inversion control of a twin rotor system in real time", in: 7th IEEE International Conference on Cybernetic Intelligent Systems, London, England, 2008, p. 1-6.

[13] Su, J.-P., Liang, C.-Y. and Chen, H.-M, "Robust control of a class of nonlinear systems and its application to a twin rotor mimo system", in: IEEE Int. Conf. on Industrial Technology, Bangkok, Thailand, 2002, p. 1272-1277.

[14] Karimi, H. R. and Motlagh, M. R. J., "Robust feedback linearization control for a non linearizable mimo 
nonlinear system in the presence of model uncertainties", in: IEEE Int. Conf. on Service Operations and Logistics, and Informatics, Shanghai, China, 2006, p. 965-970.

[15] L'opez-Martınez and M., Rubio, F., "Control of a laboratory helicopter using feedback linearization", in: European Control Conf., Cambridge, UK, 2003, p. 1-4.

[16] Mustafa, G. and Iqbal, N., "Controller design for a twin rotor helicopter model via exact state feedback linearization", in: IEEE Int. Multitopic Conf., Lahore, Pakistan, IEEE, 2004, p. 706-711.

[17] Pratap, B., Purwar and S., "State observer based robust feedback linearization controller for twin rotor mimo system", in: Int. Conf. on Control Applications, Dubrovnik, Croatia, 2012, p. 1074 1079.

[18] Pratap, B., Agrawal, A. and Purwar, S., "Optimal control of twin rotor mimo system using output feedback", in: IEEE Int. Conf. on Power, Control and Embedded Systems, Allahabad, India, 2012, p. 1-6.

[19] Li, Z., Liu, H., Zhu, B., Gao, H. and Kaynak, O., "Nonlinear robust attitude tracking control of a table-mount experimental helicopter using outputfeedback", IEEE Trans. on Industrial Electronics, v. 62 n. 9, p. 5665-5676, 2015.

[20] Khalil, H. K., Nonlinear Control, Pearson (AddisonWesley), New Jersey, USA, 2015.

[21] Rahideh, A. and Shaheed, M., "Mathematical dynamic modelling of a twin-rotor multiple inputmultiple output system", Proc. of the Institution of Mechanical Engineers, Part I: Journal of Systems and Control Engineering, v. 221, n. 1, p. 89-101, 2007.

[22] Chen, J., Behal, A. and Dawson, D. M., "Robust feedback control for a class of uncertain mimo nonlinear systems", IEEE Tr. on Automatic Control, v. 53, n. 2, p. 591-596, 2008.

[23] Atassi, A. N. and Khalil, H. K., "A separation principle for the stabilization of a class of nonlinear systems", IEEE Trans. Automat. Contr., v. 44, n. 9, p. 1672-1687, 1999.

[24] Khalil, H., "High-gain Observers in Nonlinear Feedback Control," SIAM, Philadelphia, PA, USA, 2017.

\section{Appendix A}

The full proof of the theorem is lengthy and presenting it in full would the repetition of the knowledge already available in the literature (see [22], [23], [24]), and to mainly focus on the presentation of the experimental verification on the twin rotor system, only the fundamental steps of the proof are provided below.

Proof of Theorem: First, the stability of the system is investigated under the assumption that the full state feedback is available. After that, the stability of the observer dynamics is analyzed. Finally, these two results are combined to obtain the stability of the closed loop system under the proposed output feedback controller.

The proof begins by taking the time derivative of $r(t)$ in (4) and then multiplying with $M(\theta)$ yields

$$
M \dot{r}=M\left(\ddot{\theta}_{d}+\gamma \dot{e}\right)+N(\theta, \dot{\theta}, t)-\tau
$$

where (1) was utilized. After defining auxiliary vectors $f(t), f_{d}(t), \tilde{f}(t) \in \mathbb{R}^{2}$ as

$$
\begin{gathered}
f \doteq \frac{1}{2} \dot{M} r+e+M\left(\ddot{\theta}_{d}+\gamma \dot{e}\right)+N \\
\left.f_{d} \doteq f\right|_{\theta=\theta_{d}, \dot{\theta}=\dot{\theta}_{d}} \\
\tilde{f}=f-f_{d}
\end{gathered}
$$

following expression is reached

$$
M \dot{r}=\tilde{f}+f_{d}-e-K \hat{r}-\tau_{f f}-\frac{1}{2} \dot{M} r .
$$

The structures of (A3) and (A4) allows the below bounds to be obtained

$$
\left\|f_{d}\right\| \leq c,\|\tilde{f}\| \leq \rho(\|z\|)\|z\|
$$

where $c \in \mathbb{R}^{+}$is bounding constant, $z \doteq\left[\begin{array}{ll}e^{T} & r^{T}\end{array}\right]^{T}$ is the combined error vector and $\rho(\cdot)$ is a nondecreasing function.

Substituting the full state feedback version of the control input in (7) as $\tau=K r+\tau_{f f}$ into (A5) yields

$$
M \dot{r}=\tilde{f}+f_{d}-e-K r-\tau_{f f}-\frac{1}{2} \dot{M} r
$$

The stability of the system under full state feedback being available is investigated via

$$
V \doteq \frac{1}{2} e^{T} e+\frac{1}{2} r^{T} M r
$$

which in view of (2) can be bounded as

$$
\frac{1}{2} \min \left\{1, m_{1}\right\}\|z\|^{2} \leq V \leq \frac{1}{2} \max \left\{1, m_{2}\right\}\|z\|^{2} .
$$

The time derivative of (A8) is obtained as [22]

$$
\dot{V} \leq-K_{1} V+\epsilon_{1}
$$

where $K_{1}$ and $\epsilon_{1}$ are some positive constants. Thus uniform ultimate boundedness of $\mathrm{e}(\mathrm{t})$ and $\mathrm{r}(\mathrm{t})$ are guaranteed. Having completed the stability analysis of the closed loop system under full state feedback, next the stability of the observer dynamics is analyzed. We will first define auxiliary observer errors denoted as $\eta_{1}(t)$ and $\eta_{2}(t)$ for $e(t)$ and $r(t)$, respectively as follows

$$
\eta_{1} \doteq \frac{1}{\varepsilon}(e-\hat{e})
$$




$$
\eta_{2} \doteq r-\hat{r}
$$

The time derivatives of observer errors are obtained as follows

$$
\varepsilon \dot{\eta}=A_{0} \eta+\varepsilon g
$$

where $\eta=\left[\begin{array}{ll}\eta_{1} & \eta_{2}\end{array}\right]^{T}, g=\left[\begin{array}{ll}-\gamma \eta_{1} & \dot{r}\end{array}\right]^{T}$ and

$$
A_{0}=\left[\begin{array}{cc}
-\alpha_{1} & I_{2} \\
-\alpha_{2} & O_{2 \times 2}
\end{array}\right]
$$

The following Lyapunov function is selected to investigate the stability of the unforced observer dynamics (i.e., $\varepsilon \dot{\eta}=A_{0} \eta$ )

$$
V_{0} \doteq \eta^{T} P_{0} \eta
$$

where $P_{0} \in \mathbb{R}^{4 x 4}$ is selected such as $P_{0} A_{0}+A_{0}{ }^{T} P_{0}=-I_{4}$ where $I_{4}$ is the standard identity matrix. It is easy practice to show that the right hand side of (A15) can be bounded as

$$
\lambda_{\min }\left(P_{0}\right)\|\eta\|^{2} \leq V_{0} \leq \lambda_{\max }\left(P_{0}\right)\|\eta\|^{2} .
$$

The time derivative of (A15) can be obtained as

$$
\dot{V}_{0}=\frac{\partial V_{0}}{\partial \eta} \dot{\eta} \leq-\|\eta\|^{2}
$$

For the perturbed system, the time derivative of (A15) can be obtained as

$$
\dot{V}_{0}=\frac{\partial V_{0}}{\partial \eta} \frac{1}{\varepsilon} A_{0} \eta+\frac{\partial V_{0}}{\partial \eta} g
$$

where

$$
\|g\| \leq \sigma_{1}\|\eta\|+\sigma_{2}
$$

where $\sigma_{1}, \sigma_{2} \in \mathbb{R}$ are constants.

By substituting (A17) and (A19), (A18) can be upper bounded as

$$
\dot{V}_{0} \leq-\left(\frac{1}{\varepsilon}-2\left\|P_{0}\right\| \sigma_{1}\right)\|\eta\|^{2}+2\left\|P_{0}\right\| \sigma_{2}\|\eta\| .
$$

From (A20), $\eta$ is bounded in the sense that $\|\eta\| \leq \delta$, where $\delta \in \mathbb{R}^{+}$.

The solution of $\eta$ in (A20) contains terms in the form of decreasing exponential function. So peaking phenomenon may occur [20]. One way to deal with it, is to saturate the control input when using these terms. And, inside the invariant set, the saturation function does not apply. So by using (A12), (4) can be written as

$$
M \dot{r}=\tilde{f}+f_{d}-e-K r-K \eta_{2}-\tau_{f f}-\frac{1}{2} \dot{M} r .
$$

From (A21), the time derivative of $\mathrm{V}$ in (A8) becomes

$$
\dot{V} \leq-K_{1} V+\epsilon_{1}+K\|\eta\| .
$$

Since from the observer analysis, $\|\eta\| \leq \delta$, then from (A22), following expression is obtained

$$
\dot{V} \leq-K_{1} V+\epsilon_{2}
$$

where $\epsilon_{2} \in \mathbb{R}^{+}$is a positive constant. Thus uniform ultimate boundedness of $e(t)$ and $r(t)$ are guaranteed. 